Psicologia Escolar

e Educacional
RELATO DE PRÁTICAS PROFISSIONAIS

DOI: http://dx.doi.org/10.1590/2175-35392021231489

Localizador - e231489

\title{
ATUAÇÃO EM PSICOLOGIA ESCOLAR: INTERVENÇÕES COM PROFISSIONAIS SOBRE EDUCAÇÃO SEXUAL
}

\author{
Fernanda Leite ${ }^{1} \mathbb{D}$; Maria de Fátima Pereira Alberto ${ }^{1} \mathbb{D}$; Denise Pereira dos Santos ${ }^{1} \mathbb{D}$
}

RESUMO

O objetivo deste artigo é relatar uma experiência da atuação em Psicologia Escolar em uma escola pública da cidade de João Pessoa. Ancora-se nos pressupostos da abordagem Histórico-Cultural de Vigotski, considerando o psicólogo como mediador das relações e dos conhecimentos. Em uma perspectiva de atuação preventiva e institucional, a intervenção foi realizada por profissionais da Psicologia junto a professores, tutores e oficineiros da escola, e o foco foi a educação sexual, visando instrumentalizá-los sobre o tema para possibilitar uma abordagem adequada às demandas das crianças. A experiência mostrou que a formação com os profissionais da escola tem o potencial de promover novas reflexões e possibilidades de atuação em sala de aula. Além disso, corroborou a perspectiva do papel do profissional de Psicologia como mediador das reflexões, dos processos formativos e de mudanças nas metodologias, ainda que nesse processo haja obstáculos e dificuldades.

Palavras-chave: Psicologia Escolar; formação de professores; educação sexual

\section{School psychology practice: interventions with professionals on sex education}

\begin{abstract}
The purpose of this article is to report an experience of acting in School Psychology at a public school in the city of João Pessoa. It is anchored in the assumptions of Vigotski's Historical-Cultural approach, considering the psychologist as a relationships and knowledge mediator. In a perspective of preventive and institutional action, the intervention was carried out by Psychology professionals together with teachers, tutors and school teachers, and the focus was about sex education, aiming to give them another possibility about the theme to enable an adequate approach to the demands of the students. Experience has shown that training with school professionals has the potential to promote new reflections and possibilities for acting in the classroom. In addition, it corroborated the perspective of the role of the psychology professional as a mediator of reflections, training processes and changes in methodologies, even though there are obstacles and difficulties in this process.
\end{abstract}

Keywords: School Psychology; teacher training; sex education

\section{Actuación en Psicología Escolar: Intervenciones con profesionales sobre Educación Sexual}

\section{RESUMEN}

El objetivo de este artículo es relatar una experiencia de actuación en Psicología Escolar en una escuela pública de la ciudad de João Pessoa. Se ancla en los presupuestos del abordaje Histórico-Cultural de Vygotsky, considerando el psicólogo como mediador de relaciones y conocimientos. En una perspectiva de actuación preventiva e institucional, la intervención se realizó por profesionales de la Psicología junto a profesores, tutores y ministrantes de talleres de la escuela, y el enfoque fue la educación sexual, visando instrumentalizarlos sobre el tema para posibilitarlos a abordar adecuadamente las demandas de los niños. La experiencia apuntó que la formación con los profesionales de la escuela presenta un potencial de promover nuevas reflexiones y posibilidades de actuación en sala de clase. Además de eso, corroboró la perspectiva del papel del profesional de Psicología como mediador de las reflexiones, de los procesos formativos y de cambios en las metodologías, aunque en ese proceso haya barreras y dificultades.

Palabras clave: Psicología Escolar; formación de profesores; educación sexual

\footnotetext{
${ }^{1}$ Universidade Federal da Paraíba - João Pessoa - Paraíba - Brasil; fernandaleitem@gmail.com; jfalberto89@gmail.com; denyps@ gmail.com
} 


\section{INTRODUÇÃO}

Este relato trata de uma experiência de atuação em Psicologia Escolar Educacional, com o tema educação sexual, em uma escola da rede pública municipal de João Pessoa (PB), que funciona em Tempo Integral e atende as classes da pré-escola e do Ensino Fundamental I. Tal experiência nasceu da necessidade de abordar o referido tema junto à comunidade escolar, demanda observada no cotidiano da escola, uma vez que as crianças apresentavam comportamentos, vocabulário e desenhos de cunho sexual, ante os quais a maior parte dos profissionais da instituição atuava de forma punitiva, recriminando, estigmatizando e abordando a questão pelo viés religioso.

A sexualidade é um dos temas transversais apontados pelos Parâmetros Curriculares Nacionais (PCNs) a serem trabalhados na escola, perpassando todos os níveis de ensino. Segundo os PCNs, as questões trazidas pelos alunos devem ser trabalhadas pela escola de forma crítica, reflexiva e educativa, e a sexualidade deve ser trabalhada na programação pedagógica pelas diversas áreas do conhecimento, não somente quanto às questões biológicas, mas sobretudo, no que tange aos aspectos afetivos, sociais, culturais, políticos e econômicos (Parâmetros Curriculares Nacionais [PCNs], 1997).

Furlanetto, Lauermann, Costa e Marin (2018) discutem que a conduta discriminatória dos profissionais da escola frente as manifestações da sexualidade dos alunos podem estar associadas com a falta de capacitação para lidar com a temática, o que reforça a propagação de propostas pedagógicas baseadas em concepções religiosas, higienistas e heteronormativas. Esses autores também identificaram o predomínio de trabalhos com abordagem médico-informativa, relacionada estritamente à prevenção de doenças sexualmente transmissíveis e gestação, não tendo sido identificadas atividades de educação sexual para as séries iniciais (10 ao $4^{\circ}$ ano).

Frente à demanda observada na escola em questão, duas psicólogas atuantes na instituição elaboraram uma proposta de trabalho junto aos profissionais da atividade docente (professoras, tutoras ${ }^{1}$ e oficineiros ${ }^{2}$ ), visando trabalhar a questão na perspectiva institucional, retirando o foco do problema das crianças e envolvendo outros atores do processo educacional.

Embasando essa prática, adotaram-se os pressupostos da abordagem Histórico-Cultural de Vigotski,

\footnotetext{
${ }^{1}$ Categoria profissional que surgiu com a implantação do Projeto Escola Tempo Integral na cidade de João Pessoa, com o objetivo de atender aos estudantes no horário intermediário entre os turnos (Lei no 13.035/2015).

2 Profissional que desenvolve oficinas nas instituições da rede municipal, preferencialmente nas Escolas de Tempo Integral. Objetiva complementar a formação escolar com saberes não inclusos no currículo oficial (Lei no 13.035/2015).
}

que privilegia "uma visão de homem e sociedade dialeticamente constituídos em suas relações históricas e culturais" (Marinho-Araújo, 2010, p. 27) e considera mediação psicológica nas relações sociais como uma forma de alavancar o desenvolvimento (Vigotski, 2000). De acordo com Petroni e Sousa (2014), essa abordagem permite considerar o psicólogo como mediador das relações, das possibilidades de transformação e de mudança, possíveis graças à conscientização sobre si e sobre o outro.

Em consonância com essa perspectiva, nas Referências Técnicas para atuação de Psicólogas(os) na Educação Básica, o Conselho Federal de Psicologia (CFP, 2013) defende uma Psicologia Escolar crítica e contextualizada, buscando o enfrentamento de situações naturalizadas no contexto escolar, superando explicações que culpabilizam estudantes, familiares e professores. Destaca a contribuição do psicólogo como mediador no fortalecimento do papel do professor como agente importante do processo de ensino-aprendizagem (CFP, 2013). Assim, a literatura no âmbito da Psicologia Escolar aponta para a necessidade de trabalhar com os diversos atores, passando de um enfoque clínico e curativo para uma perspectiva preventiva, visando à promoção do desenvolvimento dos atores do processo educativo (Dias, Patias, \& Abaid, 2014; Marinho-Araújo, 2010; Valle, 2003).

Nesse contexto, a proposta de atividades sobre educação sexual foi executada em etapas. A primeira etapa foi a discussão da proposta junto ao público-alvo na reunião pedagógica geral (mensal). Esse momento foi realizado a fim de discutir as ações, ouvir contribuições e eventuais dúvidas, bem como acordar atividades e cronograma. Também visou implicar os profissionais no processo de reflexão sobre o tema, tendo em vista a demanda observada na instituição. Inicialmente houve resistência de alguns membros do grupo, que focavam a necessidade de abordar o tema apenas junto às crianças e suas famílias, o que mostra na prática a resistência de trabalhar o tema por parte dos profissionais da escola por falta de formação, como afirmam Furlanetto et al. (2018).

A segunda etapa foi a realização de uma formação com as professoras, ministrada pelas psicólogas. Foram realizados dois encontros, em dias diferentes: um com as professoras da pré-escola e primeiro ano e outro com as professoras do segundo e terceiro ano (classes nas quais a demanda se apresentava de forma mais intensa). $\mathrm{Na}$ terceira etapa, realizou-se a formação com as tutoras, também em dois encontros: o primeiro, com as tutoras da pré-escola e primeiro ano; o segundo com as tutoras do segundo e terceiro anos. A quarta etapa consistiu em uma formação com os oficineiros e também ocorreu em dois encontros. No total, foram realizados 6 encontros, 
cada um com duração de uma hora.

Em todos os encontros, utilizou-se material visual, com slides e imagens, pesquisado e elaborado pelas psicólogas. Esse material versava sobre o desenvolvimento psicossexual da criança, com uma exposição acerca das fases do desenvolvimento segundo essa abordagem. Discutiu-se a respeito dos comportamentos típicos e atípicos em cada fase, destacando que alguns comportamentos observados na escola eram típicos do desenvolvimento e outros não, refletindo sobre possibilidades de abordagem com os alunos, atuando, assim, de forma preventiva (Marinho-Araújo, 2010).

Foi discutido também o significado da sexualidade, compreendendo-a como algo que se manifesta do nascimento até a morte, através da busca pelo prazer, de formas diferentes em cada fase do desenvolvimento. Assim sendo, a sexualidade é atravessada pela história, cultura, afetos e sentimentos em cada sujeito. Dessa forma, buscou-se desnaturalizar a conotação negativa das manifestações de sexualidade pelas crianças, mostrando ser um processo presente durante toda a vida, que vai além das questões biológicas (PCNs, 1997) e que, no caso da infância, necessita da abordagem adequada por parte dos adultos, não a mera repressão, superando assim a culpabilização de estudantes e familiares (CFP, 2013).

Ao final de cada encontro as(os) participantes relataram a importância de conhecer os aspectos do desenvolvimento da criança para conduzir adequadamente as situações vivenciadas no cotidiano. Algumas professoras vislumbraram a possibilidade de inserir em seu planejamento pedagógico atividades que possibilitem às crianças conhecer e nomear as partes do corpo, possibilitando trabalhar temas como respeito, consentimento e afeto. Quanto às dificuldades para a realização da atividade, uma questão consensual entre as(os) participantes foi a limitação do tempo como um entrave para um debate mais aprofundado, tendo em vista que os encontros foram realizados no turno de trabalho das(os) profissionais ${ }^{3}$ e, diante da complexidade do ambiente escolar, nem sempre foi possível cumprir os horários ou estender as formações.

A análise da experiência evidencia que os encontros com as(os) profissionais, além de um espaço de

\footnotetext{
${ }^{3}$ Para que as professoras se ausentassem da sala de aula no horário dos encontros, as tutoras assumiram as respectivas turmas uma hora antes do comum (horário em que normalmente estariam na escola, mas em contato com a equipe de especialistas para planejamento e com a professora da turma para a transição do horário). Os oficineiros ligados ao Programa Mais Educação chegavam antes do horário normal para participar dos dois encontros. Essa logística foi necessária, dada a impossibilidade de realizar tais atividades em horário oposto, já que a maioria dos profissionais possui outros vínculos de trabalho.
}

formação, constituíram-se também como um espaço de diálogo, ação coletiva e reflexão, com vistas a uma atuação preventiva envolvendo diversos atores do processo educacional, como destaca a literatura adotada nesse trabalho (Dias et al., 2014; Marinho-Araújo, 2010; Valle, 2003). Verificou-se a possibilidade de construção de novos significados e sentidos para as situações vivenciadas, como discutido por Petroni e Sousa (2014), além de atender à perspectiva de reflexão sobre esse tema prevista nos PCNs (1997).

A desnaturalização, ainda que inicial, da questão da sexualidade com os educadores provocou algumas mudanças no sentido de rever conceitos prévios, e na direção de compreender a expressão da sexualidade como uma questão histórica e social, que perpassa a subjetividade dos alunos, em conformidade com as premissas da Psicologia Histórico-Cultural (Vigotski, 2000).

Alie-se a isso a expressão verbalizada pelas educadoras, da possibilidade de novas formas ou metodologias de atuação dentro do tema, mostrando que o acesso a novas informações, à reflexão e à mediação provocada pela intervenção das psicólogas tiveram impactos no vislumbrar outras formas de atuação, o que demonstra que a mediação dos profissionais de Psicologia, no sentido de circular falas, provocar debates e recolocar questões cotidianas sob a ótica da reflexão dentro de um contexto histórico e social pode produzir impactos nas práticas institucionais (Marinho-Araújo, 2010).

\section{REFERÊNCIAS}

Conselho Federal de Psicologia. (2013). Referências Técnicas para atuação de Psicólogas (os) na Educação Básica. Brasília: CFP.

Dias, A. C. G.; Patias, N. D.; Abaid, J. L. W. (2014). Psicologia escolar e possibilidades de atuação do psicólogo: Algumas reflexões. Psicologia Escolar e Educacional, 18(1), 105-111.

Furlanetto, M. F.; Lauermann, F.; Costa, C. B.; Marin, A. H. (2018). Educação sexual em escolas brasileiras: Revisão sistemática da literatura. Cadernos de Pesquisa, 48(168), 550-571. https://doi.org/10.1590/198053145084

Lei no $13.035 / 15$ (2015, 19 de junho). Dispõe sobre o Plano Municipal de Educação 2015-2025, e dá outras providências. Prefeitura de João Pessoa. Recuperado de https://leismunicipais.com.br/plano-municipal-deeducacao-joao-pessoa-pb

Marinho-Araujo, C. M. (2010). Psicologia escolar: Pesquisa e intervenção. Em aberto, 23(83), 17-35.

Parâmetros Curriculares Nacionais (1997). Volume 10 Orientação sexual. Brasília: MEC/SEF.

Petroni, A. P.; Souza, V. L. T. (2014). Psicólogo escolar e equipe gestora: Tensões e contradições de uma parceria. Psicologia: Ciência e profissão, 34(2), 444-459. http:// 
dx.doi.org/10.1590/1982-3703000372013

Valle, L. E. L. R. (2003). Psicologia escolar: Um duplo desafio. Psicologia: Ciência e Profissão, 23(1), 22-29.
Vigotski, L. S. (2000). A formação social da mente. São Paulo: Martins Fontes. (Original publicado em 1984).

Recebido: 26 de novembro de 2019

Aprovado: 26 de março de 2020 